\title{
Screening for cardiovascular disease risk factors beginning in childhood
}

\author{
Clemens Bloetzer ${ }^{1}$, Pascal Bovet ${ }^{2}$, Joan-Carles Suris ${ }^{1,2}$, Umberto Simeoni $^{1}$, Gilles Paradis ${ }^{3}$ and Arnaud Chiolero ${ }^{2,3^{*}}$
}

\author{
* Correspondence: \\ arnaud.chiolero@chuv.ch \\ ${ }^{2}$ Division of Chronic Diseases, \\ Institute of social and preventive \\ medicine, Lausanne University \\ Hospital, Lausanne, Switzerland \\ ${ }^{3}$ Department of Epidemiology, \\ Biostatistics, and Occupational \\ Health, McGill University, Montreal, \\ Canada \\ Full list of author information is \\ available at the end of the article
}

\begin{abstract}
Cardiovascular diseases (CVD) are the leading cause of death worldwide. Individual detection and intervention on CVD risk factors and behaviors throughout childhood and adolescence has been advocated as a strategy to reduce CVD risk in adulthood. The U.S. National Heart, Lung, and Blood Institute (NHLBI) has recently recommended universal screening of several risk factors in children and adolescents, at odds with several recommendations of the U.S. Services Task Force and of the U.K. National Screening committee. In the current review, we discuss the goals of screening for CVD risk factors (elevated blood pressure, abnormal blood lipids, diabetes) and behaviors (smoking) in children and appraise critically various screening recommendations. Our review suggests that there is no compelling evidence to recommend universal screening for elevated blood pressure, abnormal blood lipids, abnormal blood glucose, or smoking in children and adolescents. Targeted screening of these risk factors could be useful but specific screening strategies have to be evaluated. Research is needed to identify target populations, screening frequency, intervention, and follow-up. Meanwhile, efforts should rather focus on the primordial prevention of CVD risk factors and at maintaining a lifelong ideal cardiovascular health through environmental, policy, and educational approaches.
\end{abstract}

Keywords: Screening, Cardiovascular disease, Children, Adolescents

\section{() BioMed Central}

\section{Introduction}

Cardiovascular diseases (CVD) are the leading cause of death worldwide with a burden of over 17 million deaths per year (31\% of the global total) [1]. They are frequent in elderly but occur rarely before the age of 60 years. Nevertheless, the pathogenic process of atherosclerosis causing CVD begins early in life, in particular during childhood and adolescence [2,3]. CVD risk factors and risk behaviors can be detected in childhood, and the extent of their presence has been linked to the severity of atherosclerosis in childhood and in adulthood [2-6]. There is also growing evidence that CVD risk factors and behaviors track to various degrees into adulthood, contributing to the risk of diseases decades later [7-11]. Therefore, individual detection and intervention on CVD risk factors and behaviors throughout childhood and adolescence has been advocated as a strategy to reduce CVD risk in adulthood $[5,6,12]$.

Hence, in a viewpoint published in 2009, McGill et al. argued that "[...] pediatricians [should be] responsible for the prevention of adult cardiovascular diseases" [6]. Indeed, as the development of CVD begins early in life and CVD risk factors are identifiable in

(C) 2015 Bloetzer et al. Open Access This article is distributed under the terms of the Creative Commons Attribution 4.0 International License (http://creativecommons.org/licenses/by/4.0/), which permits unrestricted use, distribution, and reproduction in any medium, provided you give appropriate credit to the original author(s) and the source, provide a link to the Creative Commons license, and indicate if changes were made. The Creative Commons Public Domain Dedication waiver (http://creativecommons.org/ publicdomain/zero/1.0/) applies to the data made available in this article, unless otherwise stated. 
children, he argued that individualized clinical prevention of CVD beginning in childhood should be considered. Recent recommendations of the U.S. National Heart, Lung, and Blood Institute (NHLBI) for the universal screening of several risk factors are coherent with this approach and have raised a debate about the role of CVD risk factors screening during childhood [13].

In the current review, we discuss the goals of screening for several CVD risk factors (elevated blood pressure, abnormal blood lipids, diabetes) and behaviors (smoking) in children and adolescents (below 19 years of age) and appraise critically various screening recommendations.

\section{Review}

\section{Goals and peculiarities of screening for CVD risk factors in children and adolescents}

Possible strategies for CVD prevention starting in childhood are either to prevent the development of risk factors in the first place (primordial prevention) [12] or to identify and treat children with major risk factors predisposing them to develop clinical disease several decades later (primary prevention) $[5,6]$. For the later strategy, the identification of children is possible through screening. The aim of any screening activity is to identify in a healthy population the individuals who are at increased risk for a disease or who have the disease at an early stage $[14,15]$. Once screened, these individuals are offered further testing to confirm or not the presence of the disease and, if necessary, have early intervention either to cure the disease or to prevent major consequences of the disease [15]. In CVD prevention starting in childhood, screening aims therefore to detect children carrying risk factors or risk behaviors for CVD, in order to intervene early and reduce their risk to develop clinical manifest diseases later in life.

Following the classical Wilson-Jungner criteria to assess whether any condition potentially warrants screening efforts, several conditions have to be fulfilled before recommending screening for CVD risk factors in children (Table 1) [16, 17]. A first criteria is that the prevalence of the screened condition should be known. While prevalence of smoking in children and adolescents is relatively well documented in many populations [18], much less is known on the prevalence of elevated blood pressure [19-21] and dyslipidemia [22], and the situation is even worst for diabetes [23-25]. Second, the natural history linking risk factors to CVD and the absolute risk of CVD associated with a given level of risk factors should be documented. While this risk is well documented in adults, only indirect evidence exists in children, i.e., through cohort studies having shown the association between CVD risk factors in childhood and surrogate marker of CVD in young adulthood [2-6, 26, 27]. Third, a valid and reliable screening test should

Table 1 Issues to consider when assessing the relevance of screening for cardiovascular disease (CVD) risk factors in children and adolescents. Adapted from the Wilson-Jungner criteria [17]

1. The condition should be a major and modifiable risk factor for CVD with a known prevalence in the population

2. The absolute risk of CVD associated with a given level of risk factor should be known

3. There should be a valid, reliable, and acceptable screening test to identify the risk factor in children and adolescent

4. The best screening strategy should be known (e.g., universal versus targeted screening)

5. There should be an agreement on whom to treat; further, the benefits harms, and costs of treatment should be known (treatment early in life should be associated with a better outcome than treatment later in life, accounting for lead time bias) 
exist, different screening strategies should have been evaluated, and reference values (for blood pressure, lipids, and glucose) should be available [20, 22, 28]. Finally, there should be an agreement on whom to treat and the benefits, harms, and costs of treatment should be documented. As screening engages healthy children and adolescents and since the treatment may be necessary for many decades, the balance of benefits and harms is of particular concern. Avoidance of overdiagnosis and overtreatment is of major importance in the evaluation of screening strategies [29].

\section{Recommendations for the screening for CVD risk factors in children and adolescents}

In the integrated guidelines for the cardiovascular health, experts from the NHLBI recommend the screening of several CVD risk factors at various ages during childhood (Table 2) [13]. However, most of these recommendations are at odds with the recommendations of the U.S. Preventive Services Task Force (USPSTF) [30] and of the U.K. National Screening Committee [31].

\section{Screening for elevated blood pressure}

Hypertension is a major risk factor for CVD in adults [32]. As there is growing evidence that sustained elevated blood pressure in childhood causes persistent

Table 2 Screening of cardiovascular diseases (CVD) risk factors in children and adolescents recommended by the the U.S. National Heart, Lung, and Blood Institute (NHLBI) [13], by the U.S. Preventive Services Task Force (USPSTF) [30], and by the U.K. National Screening committee [31]

\begin{tabular}{|c|c|c|c|}
\hline Screening & NHLBI recommendations & USPSTF recommendations & $\begin{array}{l}\text { U.K. National Screening } \\
\text { committee }\end{array}$ \\
\hline $\begin{array}{l}\text { Elevated blood } \\
\text { pressure }\end{array}$ & $\begin{array}{l}\text { Annual blood pressure } \\
\text { measurement in all children } \\
\text { from age } 3 \text { year; targeted } \\
\text { measurement in infants } \\
\text { with renal/urologic/cardiac } \\
\text { diagnosis or history of } \\
\text { neonatal intensive care } \\
\text { before the age of } 3 \text { year }\end{array}$ & $\begin{array}{l}\text { Evidence insufficient to assess } \\
\text { the balance of benefits and } \\
\text { harms of screening for primary } \\
\text { hypertension in asymptomatic } \\
\text { children and adolescents } \\
\text { to prevent subsequent } \\
\text { cardiovascular disease in } \\
\text { childhood or adulthood. }\end{array}$ & $\begin{array}{l}\text { Systematic population } \\
\text { screening not } \\
\text { recommended }\end{array}$ \\
\hline $\begin{array}{l}\text { Dyslipidemia/abnormal } \\
\text { blood lipids }\end{array}$ & $\begin{array}{l}\text { Universal lipid screening at } \\
\text { age 9-11 year; measurement } \\
\text { of non-fasting or fasting lipid } \\
\text { profile; targeted screening } \\
\text { according to family history } \\
\text { or other high risk condition } \\
\text { before the age of 9-11 year }\end{array}$ & $\begin{array}{l}\text { Evidence insufficient to } \\
\text { recommend for or against } \\
\text { routine screening for lipid } \\
\text { disorders in infants, children, } \\
\text { adolescents, or young adults } \\
\text { (up to age } 20 \text { ). }\end{array}$ & $\begin{array}{l}\text { Systematic population } \\
\text { screening not } \\
\text { recommended }\end{array}$ \\
\hline Diabetes & $\begin{array}{l}\text { Targeted screening at age } \\
9-11 \text { year following the } \\
\text { American Diabetes } \\
\text { Association guidelines, } \\
\text { i.e., in overweight children } \\
\text { and with two or more } \\
\text { additional risk factors for } \\
\text { diabetes [ADA 2014] }\end{array}$ & $\begin{array}{l}\text { No specific recommendation } \\
\text { for children or adolescents }\end{array}$ & $\begin{array}{l}\text { No specific } \\
\text { recommendation for } \\
\text { children or adolescents }\end{array}$ \\
\hline Smoking & $\begin{array}{l}\text { Assessment of tobacco use } \\
\text { beginning at 9-11 year }\end{array}$ & $\begin{array}{l}\text { Recommendation that primary } \\
\text { care clinicians provide } \\
\text { interventions, including } \\
\text { education or brief counseling, } \\
\text { to prevent initiation of tobacco } \\
\text { use among school-aged } \\
\text { children and adolescents. No } \\
\text { recommendation to screen } \\
\text { for tobacco use. }\end{array}$ & $\begin{array}{l}\text { No specific } \\
\text { recommendation for } \\
\text { children or adolescents }\end{array}$ \\
\hline
\end{tabular}


cardiovascular alterations and tracks into adulthood, several guidelines recommended universal screening for hypertension in childhood starting at the age of three [13, 33, 34]. However, recent, exhaustive reviews have concluded that the evidence to recommend universal hypertension screening in childhood was limited [21, 35, 36].

While it seems reasonable to assume that children with hypertension are at increased risk for CVD in adult life, no study has lasted long enough to link directly elevated blood pressure in childhood to the risk of CVD in adulthood. The absolute risk of CVD associated with a given pediatric blood pressure level is, indeed, unknown $[20,21]$. As a consequence, a BP threshold above which intervention is beneficial is not known in children. Further, although lifestyle or pharmacologic interventions for hypertension in childhood have been shown to decrease blood pressure in the short-term, the long-term benefits and harm are unknown [20]. It is therefore unknown whether potential harms outweigh the expected benefices.

Due to the length of the pathogenic process and since CVD occurs rarely before the age of 60, one can assume that no randomized controlled trial to assess the direct effect of any BP reduction intervention in childhood on the absolute risk of CVD will be ever conducted. In a cost-effective simulation study, neither universal screening with treatment of those with hypertension or treatment of those with end-organ injury, nor targeted screening in overweight adolescents was shown to perform better than population-based interventions [37].

A further major issue is that CVD risk factors like blood pressure or blood lipids are relatively weak CVD predictors (Fig. 1) [14, 38]. Indeed, the discriminative power of blood pressure or blood lipids for having or not a CVD later in life is weak. For instance, while individuals with elevated blood pressure have a higher risk of CVD, many cases of CVD will occur in individuals with normal blood pressure. This is why high risk prevention strategies based notably on screening are not sufficient to prevent CVD in the population, what requires population-based prevention strategies to have a favorable effect on the distribution of risk factors in the whole population [39, 40].

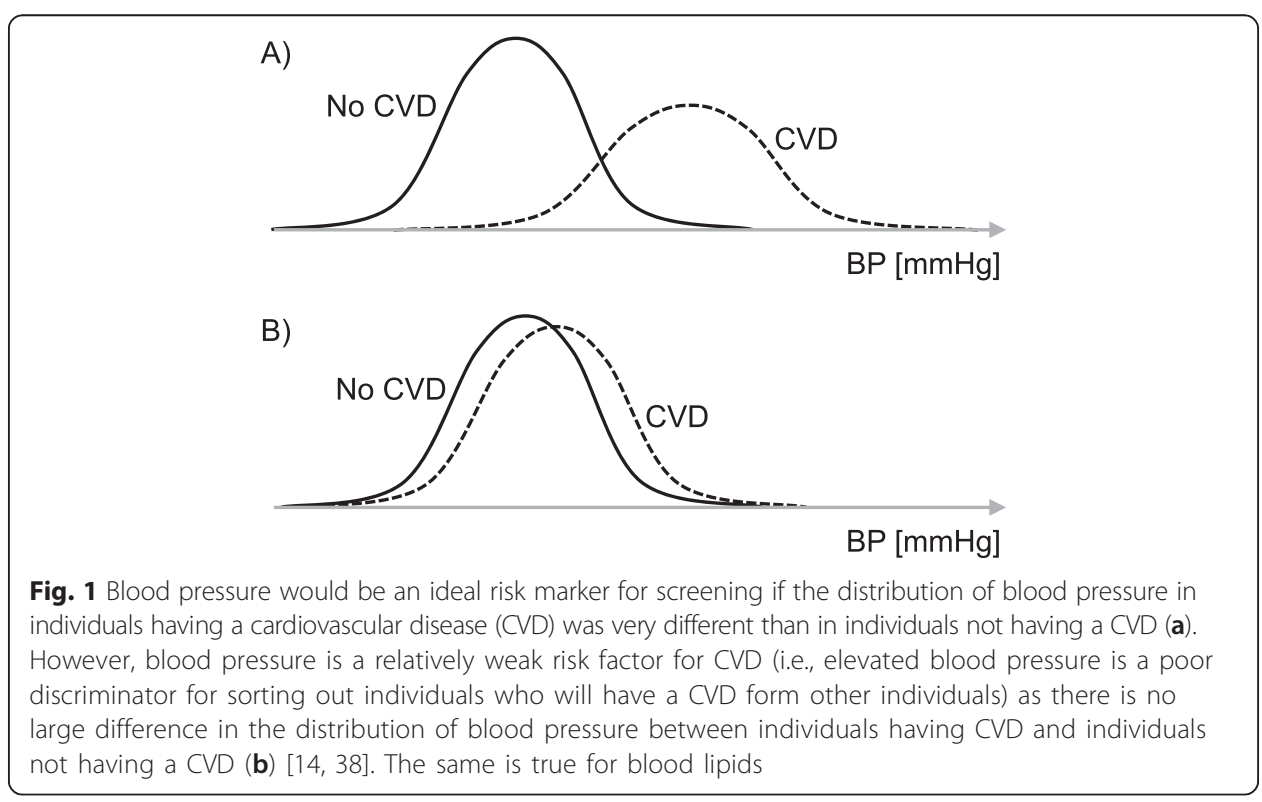




\section{Screening for dyslipidemia}

In adults, high levels of total cholesterol and low density lipoprotein-cholesterol (LDL-C) are important risk factors for coronary heart disease. Further, there is also good evidence that lipid-lowering treatment substantially decreases the incidence of coronary heart disease in persons with dyslipidemia [41]. Therefore, the USPSTF strongly recommends blood lipids screening in men aged 35 and women aged 45 [42]. It is also well known that the effect of lipid-lowering treatment will depend on the absolute risk of CVD. As age is the main determinant of CVD risk, the USPSTF does not recommend screening before the age of 35 in men and 45 in women as below that age, the absolute risk of CVD is low and the benefit of treatment is expected to be minimal. In younger adults, the USPSTF recommends targeted screening only in high risk individuals, i.e., having a family history of CVD at a young age, smokers, or a personal history of diabetes or hypertension [42].

In children, the USPSTF argue that evidence is insufficient to recommend for or against routine screening for lipid disorders in infants, children, adolescents, or young adults (up to age 20) [43] (an update of this recommendation is ongoing). The UK National Screening committee does not recommend screening in children. At odds with this recommendation, the NHLBI recommended in 2012 universal screening for dyslipidemia in children aged 9-11 years old and targeted screening in high risk children at younger age [13]. These recommendations have raised an important debate, with strong doubts about their efficiency and concerns about their potential harms [44-47].

Following the NHLBI guidelines, the primary goal of universal screening is identifying cases of familial hypercholesterolemia (FH) [46]. FH is indeed the most prevalent primary dyslipidemia in children, reaching 1 in 250-500 of individuals [48]. It is a severe form of dyslipidemia associated with a very high risk of CVD; the cumulative risk for coronary heart disease is estimated to be greater than $50 \%$ in men by the age of 50 and $30 \%$ in women by the age of 60 [49]. Statin treatment in these children is efficient (with beneficial effect shown on surrogates markers of CVD) and safe [46]. However, while lifetime treatment is potentially required, long term safety is not established.

Targeted screening to high risk children (e.g., with obesity or a family history of CVD at an early age) and cascade screening (i.e., systematic screening of close relatives of previously diagnosed index cases) has been proposed as alternative to universal screening for the detection of FH $[48,49]$. For instance, the UK National Institute for Health and Clinical Excellence recommends cascade screening using a combination of genetic testing and LDL cholesterol concentration measurement of close (first-, second-, and third-degree) biological relatives of people with FH [49]. Pediatricians favor targeted screening as shown by the higher proportion of test for blood lipids among children with obesity in the United States [50].

\section{Screening for diabetes}

Hyperglycemia accelerates atherosclerosis and is a cause of CVD [51, 52]. Screening for abnormal blood glucose (impaired fasting glucose or impaired glucose tolerance) and type 2 (T2DM) diabetes mellitus is recommended by the USPSTF in adults at high risk of diabetes [53]. The goal of screening in adults is to prevent progression of abnormal blood glucose to T2DM and long term complications of diabetes, either microvascular 
(retinopathy, neuropathy, nephropathy) or macrovascular (i.e., CVD) complications. Early treatment of T2DM in adults has been shown to be associated with a lower rate of microvascular complications.

In children, type 1 (T1DM) diabetes mellitus is much more frequent than T2DM [23-25]. T1DM is a different condition than T2DM and characterized by a lack of insulin secretion by the pancreas. T1DM develops rapidly, sometimes with dramatic consequences, and there is no true preclinical indicator that could be easily targeted for screening. Due to the increasing prevalence of obesity, abnormal blood glucose and T2DM is expected to be increasingly frequent in children and adolescents [25, 54]. Elevated blood glucose in childhood is a predictor of prediabetes and T2DM in adulthood [54].

While there is no specific recommendation by the USPSTF or by the UK National Screening committee for the screening of abnormal blood glucose and T2DM, several guidelines recommend targeted screening for glucose intolerance in children at high risk, e.g., due to the presence of overweight or other risk factors (ethnicity, family history of T2DM, signs of insulin resistance or conditions associated with, maternal gestational diabetes) $[13,55]$. No guidelines recommend universal screening in children and adolescents.

\section{Screening for smoking}

Smoking is highly addictive and a major risk factor for CVD [56]. Worldwide, it kills over 5 million persons per year [56]. Helping smoking cessation is efficient in adults and the USPSTF recommends that clinicians ask all adults about tobacco use and provide tobacco cessation interventions for those who use tobacco products [57]. As most adult smokers started to smoke during late childhood and adolescence [58], interventions to prevent initiation or help cessation of smoking during childhood and adolescence are warranted. Cochrane reviews have shown that school- and family-based interventions can help prevent smoking initiation in children and adolescents $[59,60]$.

Evidence on the effect of interventions for smoking cessation in adolescents is less convincing [58, 61, 62]. The American Medical Association's (AMA) Guidelines for Adolescent Preventive Services (GAPS) recommend that "all adolescents should be asked annually about their use of tobacco products including cigarettes and smokeless tobacco" [61]. However, a recent systematic review assessing evidence for the efficacy and harms of primary-care interventions to reduce tobaccos use in children and adolescents has shown that smoking initiation could be prevented by behavior based interventions but that neither behavior-based nor pharmacologic interventions improved cessation rate [62]. Based on this review, the USPSTF recommends that primary care clinicians provide interventions, including education or brief counseling, to prevent initiation of tobacco use among school-aged children and adolescents [63]. The USPSTF does not recommend screening for smoking.

\section{Conclusion}

Since 50 years, the prevention of CVD is a success story among adults of high-income countries. Indeed, CVD mortality rates have sharply decreased, e.g., in the UnitedStates, Canada or Switzerland, in both sexes and in all age strata of the population [64]. Population-based as well as high-risk prevention strategies have contributed to this 
large decrease in CVD [65]. It is increasingly accepted that CVD prevention strategies should include children as well as adults [66]. Nevertheless, even if the pathogenic process of CVD originates in childhood, it does not imply that the model of adult CVD clinical prevention strategies is applicable to children. Our review suggests indeed that there is no compelling evidence to recommend universal screening for elevated blood pressure, abnormal blood lipids, abnormal blood glucose, or smoking in children and adolescents. Targeted screening of these risk factors could be useful but specific screening strategies have to be evaluated [44, 45, 67].

Research is needed to identify target populations, screening frequency, intervention and follow-up. Further, research is needed to assess the effect of early life screening and treatment of CVD risk factors. Since CVD are remote outcomes, rarely occurring before the age of 60 years, the effect of early life screening and treatment should be tested in trials using more proximal outcomes, i.e., proxies such as carotid intimamedia thickness which have been shown to be associated with CVD risk factors in childhood and adolescence. Meanwhile, efforts should rather focus on the primordial prevention of CVD risk factors [12] and at maintaining a lifelong ideal cardiovascular health through environmental, policy, and educational approaches [68].

Abbreviation

CVD: Cardiovascular diseases; BP: Blood pressure; USPSTF: U.S. Preventive Services Task Force; NHLBI: U.S. National Heart Lung, and Blood Institute.

\section{Competing interests}

The authors declare that they have no any competing interests

\section{Authors' contributions}

CB and AC conducted the literature search and drafted the manuscript; PB, JSC, US, and GP reviewed the draft and made substantial suggestions. All authors read and approved the final manuscript.

\section{Acknowledgements}

There was no specific funding.

\section{Author details}

${ }^{1}$ Department of Pediatrics, Lausanne University Hospital, Lausanne, Switzerland. ²Division of Chronic Diseases, Institute of social and preventive medicine, Lausanne University Hospital, Lausanne, Switzerland. ${ }^{3}$ Department of Epidemiology, Biostatistics, and Occupational Health, McGill University, Montreal, Canada.

Received: 18 February 2015 Accepted: 2 October 2015

Published online: 05 November 2015

\section{References}

1. WHO. Global Health Observatory (GHO): NCD mortality and morbidity. Available at: www.who.int/gho/ncd/ mortality_morbidity/en. Accessed 16 Sept 2014.

2. Berenson GS, Wattigney WA, Tracy RE, Newman WP, Srinivasan SR, Webber LS, et al. Atherosclerosis of the aorta and coronary arteries and cardiovascular risk factors in persons aged 6 to 30 years and studied at necropsy (The Bogalusa Heart Study). Am J Cardiol. 1992;70(9):851-8.

3. Berenson GS, Srinivasan SR, Bao W, Newman 3rd WP, Tracy RE, Wattigney WA. Association between multiple cardiovascular risk factors and atherosclerosis in children and young adults. The Bogalusa heart study. N Engl J Med. 1998;338(23):1650-6.

4. Li S, Chen W, Srinivasan SR, Bond MG, Tang R, Urbina EM, et al. Childhood cardiovascular risk factors and carotid vascular changes in adulthood: the Bogalusa heart study. JAMA. 2003;290(17):2271-6.

5. McGill Jr HC, McMahan CA, Gidding SS. Preventing heart disease in the 21 st century: implications of the pathobiological determinants of atherosclerosis in youth (PDAY) study. Circulation. 2008;117(9):1216-27.

6. McGill HC, McMahan CA, Gidding SS. Are pediatricians responsible for prevention of adult cardiovascular disease? Nat Clin Pract Cardiovasc. 2009;6(1):10-1.

7. Chen $X$, Wang Y. Tracking of blood pressure from childhood to adulthood: a systematic review and meta-regression analysis. Circulation. 2008;117(25):3171-80

8. Telama R, Yang X, Viikari J, Välimäki I, Wanne O, Raitakari O. Physical activity from childhood to adulthood: a 21-year tracking study. Am J Prev Med. 2005;28(3):267-73.

9. Freedman DS, Mei Z, Srinivasan SR, Berenson GS, Dietz WH. Cardiovascular risk factors and excess adiposity among overweight children and adolescents: the Bogalusa heart study. J Pediatr. 2007;150(1):12-7. e2. 
10. Friedman LA, Morrison JA, Daniels SR, McCarthy WF, Sprecher DL. Sensitivity and specificity of pediatric lipid determinations for adult lipid status: findings from the Princeton lipid research clinics prevalence program follow-up study. Pediatrics. 2006;118(1):165-72.

11. United States. Public Health Service. Office on Smoking and Health. The health benefits of smoking cessation. The reports of the surgeon general, DHHS Publication No. (CDC). 1990. p. 90-8416. http://profiles.nlm.nih.gov/NN/B/B/C/T/.

12. Labarthe DR. Prevention of cardiovascular risk factors in the first place. Prev Med. 1999:29(6 Pt 2):S72-8

13. ational Heart, Lung, and Blood Institute (NHLBI). Integrated guidelines for cardiovascular health and risk reduction in children and adolescents. 2012. www.nhlbi.nih.gov/guidelines/cvd_ped/index.htm.

14. Wald NJ, Hackshaw AK, Frost CD. When can a risk factor be used as a worthwhile screening test? BMJ. 1999:319(7224):1562-5.

15. Raffle AE, Gray JAM. Screening: evidence and practice. Oxford: Oxford University Press; 2007.

16. Grimes DA, Schulz KF. Uses and abuses of screening tests. Lancet. 2002;359:881-4.

17. Wilson JMG, Jungner G. Principles and practice of screening for disease. Geneva: WHO; 1968. www.who.int/ bulletin/volumes/86/4/07-050112BP.pdf.

18. de Looze M, ter Bogt T, Hublet A, Kuntsche E, Richter M, Zsiros E, et al. Trends in educational differences in adolescent daily smoking across Europe, 2002-10. Eur J Public Health. 2013;23(5):846-52.

19. Chiolero A, Cachat F, Burnier M, Paccaud F, Bovet P. Prevalence of hypertension in schoolchildren based on repeated measurements and association with overweight. J Hypertens. 2007;25(11):2209-17.

20. McCrindle BW. Assessment and management of hypertension in children and adolescents. Nat Rev Cardiol. 2010;7(3):155-63.

21. Chiolero A, Bovet P, Paradis G. Screening for elevated blood pressure in children and adolescents: a critical appraisal. JAMA Pediatr. 2013;167(3):266-73.

22. De Henauw S, Michels N, Vyncke K, Hebestreit A, Russo P, Intemann T, et al. Blood lipids among young children in Europe: results from the European IDEFICS study. Int J Obes. 2014;38(2):S67-75.

23. Pinhas-Hamiel $\mathrm{O}$, Zeitler $\mathrm{P}$. Acute and chronic complications of type 2 diabetes mellitus in children and adolescents. Lancet. 2007;369(9575):1823-31.

24. D'Adamo E, Caprio S. Type 2 diabetes in youth: epidemiology and pathophysiology. Diabetes Care. 2011;34 Suppl 2:S161-5.

25. Dabelea D, Mayer-Davis EJ, Saydah S, Imperatore G, Linder B, Divers J, et al. Prevalence of type 1 and type 2 diabetes among children and adolescents from 2001 to 2009. JAMA. 2014;311(17):1778-86.

26. McMahan CA, Gidding SS, Viikari JS, Juonala M, Kähönen M, Hutri-Kähönen N, et al. Association of pathobiologic determinants of atherosclerosis in youth risk score and 15-year change in risk score with carotid artery intima-media thickness in young adults. Am J Cardiol. 2007;100(7):1124-9.

27. Raitakari OT, Juonala M, Kahonen M, Taittonen L, Laitinen T, Maki-Torkko N, et al. Cardiovascular risk factors in childhood and carotid artery intima-media thickness in adulthood: the cardiovascular risk in young Finns study. JAMA. 2003;290(17):2277-83.

28. Chiolero A. The quest for blood pressure reference values in children. J Hypertens. 2014:32(3):477-9.

29. Coon ER, Quinonez RA, Moyer VA, Schroeder AR. Overdiagnosis: how our compulsion for diagnosis may be harming children. Pediatrics. 2014;134(5):1013-23.

30. U.S. Preventive Services Task Force (USPSTF). Recommendations. Available at : www.uspreventiveservicestaskforce.org/ BrowseRec/Index/browse-recommendations. Accessed 14 Oct 2014

31. U.K. National Screening Committee. Policies. Available at : www.screening.nhs.uk/policydb.php (Accessed 14 Oct 2014)

32. Lawes CM, Vander Hoorn S, Rodgers A, International Society of Hypertension. Global burden of blood-pressurerelated disease, 2001. Lancet. 2008:371(9623):1513-8.

33. National High Blood Pressure Education Program Working Group on High Blood Pressure in Children and Adolescents. The fourth report on the diagnosis, evaluation, and treatment of high blood pressure in children and adolescents. Pediatrics. 2004;114:555-76.

34. Lurbe E, Cifkova R, Cruickshank JK, et al. Management of high blood pressure in children and adolescents: recommendations of the European Society of Hypertension. J Hypertens. 2009;27:1719-42.

35. Thompson M, Dana T, Bougatsos C, Blazina I, Norris SL. Screening for hypertension in children and adolescents to prevent cardiovascular disease. Pediatrics. 2013;131(3):490-25.

36. Moyer VA, U.S. Preventive Services Task Force. Screening for primary hypertension in children and adolescents: U.S. Preventive Services Task Force recommendation statement. Ann Intern Med. 2013;159(9):613-9.

37. Wang YC, Cheung AM, Bibbins-Domingo K, Prosser LA, Cook NR, Goldman L, et al. Effectiveness and costeffectiveness of blood pressure screening in adolescents in the United States. J Pediatr. 2011:158(2):257-64.

38. Law M, Wald N, Morris J. Lowering blood pressure to prevent myocardial infarction and stroke: a new preventive strategy. Health Technol Assess. 2003;7(31):1-94.

39. Rose G. Sick individuals and sick populations. Int J Epidemiol. 1985;14(1):32-8.

40. Rose G. Strategy of preventive Medicine. Oxford: Oxford University Press; 1992. Reedited in 2008

41. Collaboration ERF, Di Angelantonio E, Sarwar N, Perry P, Kaptoge S, Ray KK, et al. Major lipids, apolipoproteins, and risk of vascular disease. JAMA. 2009;302(18):1993-2000.

42. US Preventive Services Task Force. Screening for lipid disorders in adults. 2008.Available at: www.uspreventive servicestaskforce.org/uspstf/uspschol.htm. Accessed 20 Nov 2014

43. US Preventive Services Task Force (2007). Lipid Disorders in Children: Screening. Available at: www.uspreventive servicestaskforce.org/Page/Topic/recommendation-summary/lipid-disorders-in-children-screening. Accessed 20 Nov 2014

44. Gillman MW. Changing the conversation regarding pediatric cholesterol screening: the rare disease paradigm Arch Pediatr Adolesc Med. 2012;166(12):1097-8.

45. Gillman MW, Daniels SR. Is universal pediatric lipid screening justified? JAMA. 2012;307(3):259-60

46. McCrindle BW, Kwiterovich PO, McBride PE, Daniels SR, Kavey RE. Guidelines for lipid screening in children and adolescents: bringing evidence to the debate. Pediatrics. 2012;130(2):353-6. 
47. Newman TB, Pletcher MJ, Hulley SB. Overly aggressive new guidelines for lipid screening in children: evidence of a broken process. Pediatrics. 2012;130(2):349-52.

48. Ademi Z, Watts GF, Pang J, Sijbrands EJ, van Bockxmeer FM, O'Leary P, et al. Cascade screening based on genetic testing is cost-effective: evidence for the implementation of models of care for familial hypercholesterolemia. J Clin Lipidol. 2014;8(4):390-400.

49. Ned RM, Sijbrands EJ. Cascade screening for familial hypercholesterolemia (FH). PLoS Curr. 2011;3, RRN1238.

50. Margolis KL, Greenspan LC, Trower NK, Daley MF, Daniels SR, Lo JC, et al. Lipid screening in children and adolescents in community practice: 2007 to 2010. Circ Cardiovasc Qual Outcomes. 2014;7(5):718-26.

51. Collaboration ERF, Sarwar N, Gao P, Seshasai SR, Gobin R, Kaptoge S, et al. Diabetes mellitus, fasting blood glucose concentration, and risk of vascular disease: a collaborative meta-analysis of 102 prospective studies. Lancet. 2010;375(9733):2215-22.

52. Krantz JS, Mack WJ, Hodis HN, et al. Early onset of subclinical atherosclerosis in young persons with type 1 diabetes. J Pediatr. 2004;145(4):452-7.

53. US Preventive Services Task Force (2014). Abnormal Glucose and Type 2 Diabetes Mellitus in Adults: Screening. Available at: www.uspreventiveservicestaskforce.org/Page/Document/RecommendationStatementDraft/screeningfor-abnormal-glucose-and-type-2-diabetes-mellitus. Accessed 20 Nov 2014).

54. Nguyen QM, Srinivasan SR, XU JH, Chen W, Berenson GS. Fasting plasma glucose levels within the normoglycemic range in childhood as a predictor of prediabetes and type 2 diabetes in adulthood: the Bogalusa Heart Study. Arch Pediatr Adolesc Med. 2010;164(2):124-8.

55. American Diabetes Association. Standards of medical care in diabetes-2014. Diabetes Care. 2014;37(1):S14-80.

56. WHO Global Report. Mortality Attributable to Tobacco. WHO 2012. Available at: www.who.int/tobacco/ publications/surveillance/rep_mortality_attributable/en/. Accessed 20 Nov 2014.

57. U.S. Preventive Services Task Force. Counseling and interventions to prevent tobacco use and tobacco-caused disease in adults and pregnant women: U.S. Preventive services task force reaffirmation recommendation statement. Ann Intern Med. 2009;150(8):551-5.

58. Stanton A, Grimshaw GM. Tobacco cessation interventions for young people. Cochrane Database Syst Rev. 2013;8, CD003289.

59. Thomas RE, Baker P, Lorenzetti D. Family-based programmes for preventing smoking by children and adolescents. Cochrane Database Syst Rev. 2007;1, CD004493.

60. Thomas RE, McLellan J, Perera R. School-based programmes for preventing smoking. Cochrane Database Syst Rev. 2013;4, CD001293.

61. Elster A. The american medical association guidelines for adolescent preventive services. Arch Pediatr Adolesc Med. 1997;151(9):958-9.

62. Patnode CD, O'Connor E, Whitlock EP, Perdue LA, Soh C, Hollis J. Primary care-relevant interventions for tobacco use prevention and cessation in children and adolescents: a systematic evidence review for the U.S. Preventive Services Task Force. Ann Intern Med. 2013;158(4):253-60.

63. Moyer VA, U.S. Preventive Services Task Force. Primary care interventions to prevent tobacco use in children and adolescents: U.S. Preventive Services Task Force recommendation statement. Ann Intern Med. 2013;159(8):552-7.

64. Araújo F, Gouvinhas C, Fontes F, La Vecchia C, Azevedo A, Lunet N. Trends in cardiovascular diseases and cancer mortality in 45 countries from five continents (1980-2010). Eur J Prev Cardiol. 2013;21(8):1004-17.

65. Young F, Capewell S, Ford ES, Critchley JA. Coronary mortality declines in the U.S. between 1980 and 2000 quantifying the contributions from primary and secondary prevention. Am J Prev Med. 2010;39(3):228-34.

66. Cutler JA, Roccella EJ. Salt reduction for preventing hypertension and cardiovascular disease: a population approach should include children. Hypertension. 2006;48(5):818-9.

67. Bloetzer C, Paccaud F, Burnier M, Bovet P, Chiolero A. Performance of parental history for the targeted screening of hypertension in children. J Hypertens. 2015;33(6):1167-73.

68. Lloyd-Jones DM, Hong Y, Labarthe D, Mozaffarian D, Appel LJ, Van Horn L, et al. Defining and setting national goals for cardiovascular health promotion and disease reduction: the american heart Association's strategic impact goal through 2020 and beyond. Circulation. 2010;121(4):586-613.

\section{Submit your next manuscript to BioMed Central and take full advantage of:}

- Convenient online submission

- Thorough peer review

- No space constraints or color figure charges

- Immediate publication on acceptance

- Inclusion in PubMed, CAS, Scopus and Google Scholar

- Research which is freely available for redistribution

Submit your manuscript at www.biomedcentral.com/submit 